\title{
Cryosurgery in a dermatology setup: a hospital based study
}

\section{Deeptara Pathak Thapa, Anil Kumar Jha, Shristi Shrestha, Smita Joshi}

\author{
Department of Dermatology, Nepal Medical College and Teaching Hospital, Kathmandu, Nepal
}

Corresponding author: Dr. Deeptara Pathak Thapa, E-mail: drdeeptarapathak@yahoo.com

\begin{abstract}
Background: Cryosurgery is the well-aimed and controlled destruction of diseased tissue by application of cold. It has been shown to be effective and efficient in various skin diseases. We studied the indications and outcome of this modality of treatment in our set up. Materials and Method: All patients who were subjected to cryosurgery for different clinical indications were included in the study. Results: There were total of 133 patients. Commonest age group presentation (between 16 to 25 years) constituted about $42 \% .52 \%$ of patients were students. There were total of $91 \%$ who were from Kathmandu remaining 9\% were from outside of Kathmandu Valley. Cryosurgery was indicated commonly in warts for $82 \%$ patients followed by $12 \%$ for keloid \& hypertrophic scar, benign conditions in $4 \%$ and in premalignant conditions for $2 \%$ patients. Number to treatment (or sessions) for indicated disease with resolution of disease was single in $81 \%$ patients followed by between 2 to 5 treatment session in 14\% and more than 5 treatments was necessary in $5 \%$. Side effects like pain was seen in 64\% patients, erythema in $8 \%$ and blistering $4 \% .24 \%$ patients did not have any side effect. Conclusion: Cryotherapy is considered as one of the effective modality of treatment for various skin conditions with various limitations. Further prospective clinical trial with large population group should be carried out.
\end{abstract}

Key words: Cryosurgery; Liquid nitrogen; Keloid; Warts

\section{INTRODUCTION}

Cryosurgery is a procedure in which there is controlled destruction of diseased tissue by application of cold. It provides an effective and efficient treatment option for various skin diseases like infections, benign skin growth, premalignant condition and some malignant skin tumors and provides high cure rates and good cosmetic results with a few contra-indications and low incidence of complication [1]. The biological changes that occur during and after cryosurgery is caused by tissue injury which is induced by cell freezing and by the vascular stasis followed by cryo-reaction, the immunological phase. There are no study regarding use of cryosurgery in dermatology done in the literature of Nepal. So with this study we want to know the clinical indications and outcome of the procedure.

\section{MATERIALS AND METHOD}

All patients who visited Dermatology outpatient department of Nepal Medical College and Teaching hospital and were subjected to cryosurgery for different clinical indications were included in the study. Details of patients who had undergone cryotherapy, their demographic profile including, name, Hospital reference number, age, sex, address, occupation, marital status, indication for treatment, number of treatment, side effects were obtained from the data maintained in the dermatology department outpatient record from fiscal year June 2016-June 2017. Patients having other systemic illness, Pregnancy or lactating were excluded from the study. Statistical study using SPSS version 16 with descriptive analysis was carried out.

\section{RESULT}

There were total of 133 patients who underwent cryosurgery during the one year study period. $42 \%$ patients were between 16 to 25 years, followed by $27 \%$ patients between 26 to 35 years, $25 \%$ less than 15 years and $6 \%$ more than 36 years. Cryosurgery was indicated mostly in students (52\%) followed by $24 \%$

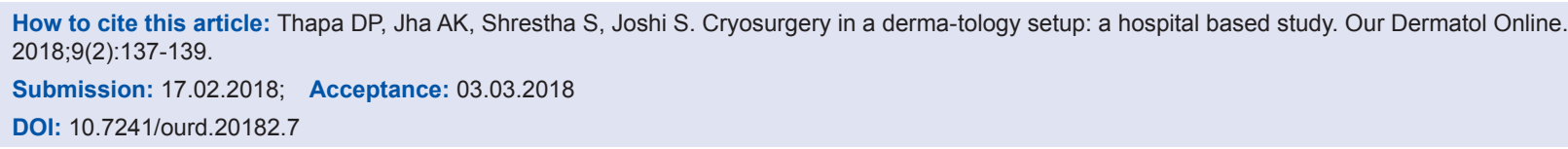


who were housewife, in $22 \%$ who were employed and in $2 \%$ unemployed. There were total of $91 \%$ who were from Kathmandu, out of which $68 \%$ from south of Kathmandu, $13 \%$ from north of Kathmandu, 6\% from west of Kathmandu and 4\% east of Kathmandu, the remaining 9\% were from outside of Kathmandu Valley.

Cryosurgery was indicated commonly in warts $82 \%$ out of which plantar warts were in $36 \%$, verruca vulgaris $34 \%$, palmar $14 \%$, genital $13 \%$ and periungual $3 \%$ patients. Second common indication was in keloid, hypertrophic scar and post burn scar, which together constituted $12 \%$ followed by in benign conditions like acne cyst, corn, De Morgan spots, Seborrheic keratoses, linear porokeratosis in $4 \%$ and in premalignant conditions like Bowes disease in $2 \%$. The duration of the disease was less than one month in $46 \%$, between 6 month to 1 year in $33 \%$ and more than one year in $21 \%$ patients. Number of sessions required to treat the indicated disease with resolution of disease was single in $81 \%$ patients followed by between 2 to 5 treatment sessions in $14 \%$ and more than 5 sessions was necessary in $5 \%$. Side effects like pain was seen in $64 \%$ of the patients, erythema in $8 \%$ and blistering in $4 \%$ patients. There was no side effects seen in $24 \%$.

\section{DISCUSSION}

Cryosurgery is a well-aimed and controlled destruction of diseased tissue by application of cold. It has been shown to be effective and efficient in various skin diseases, provides high cure rates and good cosmetic results with a few contra-indications and low incidence of complications. The biological changes that occur during cryosurgery are tissue injury in which intracellular ice formation damages mitochondria and endoplasmic reticulum, leads to an irreversible cell destruction known as homogenous nucleation, followed by heterogenous nucleation, vascular stasis and tissue anoxemia resulting in ischemic necrosis [2].

There are still only few studies on the immunological cutaneous response to cryosurgery. Langerhans cell activity was found to be increased in mouse skin after treatment. In keloid cryosurgery leads to tenascin expression while IFN-g expression was depleted $[3,4]$. Cryosurgery is considered the treatment of choice in hypertrophic scars, keloids, infantile hemangioma, isolated actinic keratoses and granuloma annulare and an alternative therapy for various conditions like warts, superficial basal cell carcinoma and Kaposi sarcoma.
There is increasing trend for use of cryosurgery in cutaneous malignancy, premalignant conditions and benign neoplastic diseases [5].

In a study by Menedez et al. total cure rate was seen in $87.7 \%$ with various cutaneous indications. In cutaneous warts cryotherapy was found to be useful in $50 \%-70 \%$. In our study we found effective in $82 \%$. Stefanaki et al found $67.3 \%$ improvement in children treated with cryotherapy [6-7]. A comparative study with immunotherapy and cryotherapy, Kozeimeh et al found immunotherapy more effective then cryotherapy [8]. Punch reduction prior to cryotherapy in patients with viral warts showed decrease the number and cost of treatment by reducing the size of warts and inducing local inflammation to accelerate resolution [9].

In a questionnaire based study cryotherapy was the first choice of treatment for $73 \%$ responders in palmar warts, $49 \%$ in plantar warts and $72 \%$ in warts on other location [10]. In our study we found cryotherapy being used for plantar warts (36\%), verruca vulgaris (34\%), palmar (14\%), genital (13\%) and periungual $(3 \%)$.

Meymandi et al in a comparative study found that cryotherapy as well as intense pulse light laser were equally effective in treatment of hypertrophic scar and keloid [11]. Cryotherapy in combination with intralesional steroid has been the most popular classic treatment for both keloid and hypertrophic scars. It also helpful to heal small scars like acne scars. Moreover, the common side effect of cryotherapy is permanent hypopigmentation. Although it is used in multiple sessions every month, the least number of sessions the better chance for post-operative healing. Further, the success rates after 2 sessions have ranged from 30 to $75 \%$ either by using spray or contact cryosurgery with liquid nitrogen, and it is lower in keloid than in hypertrophic scars [12-13]. In a clinical trial, $79.5 \%$ of patients responded very well with a volume reduction of the initial mass of greater than $80 \%$ after a median of 3 treatments (range 1-9). In our study it was indicated in $12 \%$ patients. A good result was obtained in $14.5 \%$ of lesions, while results were unsatisfactory in $6 \%$ of cases. The main adverse effects reported were atrophic depressed scars and residual hypo pigmentation $75 \%$ of cases. No recurrences arose during the follow-up period (12-72 months) as per Russian et al. [14]. In our study we found side effects like pain in $64 \%$ of the patients, erythema in $8 \%$ and blistering in $4 \%$ patients. There were no side effects in $24 \%$. 
Cryotherapy also has been tried and found to be useful in parasitic infection like leishmaniasis. In a randomized clinical trial, Farajzadeh found that cryotherapy in combination with oral terbinafine was less effective then cryotherapy with systemic Meglumine Antimoniate. In a meta-analysis, per lesion efficacy of $67.3 \%$ and $67.7 \%$ were reported for cryotherapy and pentavalent antimonials respectively [15]. In a case series for multiple recurrent Actinic keratosis sequential treatment of diclofenac 3\% gel with cryotherapy was found to be an effective treatment [16].

In a multricentric intralesional randomized trial cryotherapy was found to have higher efficacy than topical methyl aminolaevulinate- photodynamic therapy by Kaufmann et al. [17]. A case series of loco-regional cutaneous metastasis of melanoma combination therapy of cryosurgery and imiquimod was found to be successful [18]. Cryotherapy as a useful procedure used for other dermatological indications in case series and case reports mentioned in the literature are Xanthelasma palpebrarum, dermatofibrosarcoma protuberans, Refractory cutaneous Rosa Dorfman disease, cutaneous sporotrichosis, and also in oral lesions in children [19-20].

In our study the other indications were benign conditions like acne cyst, corn, De Morgan spots, Seborrheic keratoses, linear porokeratosis was seen in $4 \%$ and in premalignant conditions like Bowes disease in $2 \%$ patients.

There are various limitations in our study, being retrospective we couldn't assess the complete clearance of the disease, follow-up of the patients and recurrence rates.

\section{CONCLUSION}

Cryotherapy is one of the effective modality of treatment for various skin disease ranging from warts, hypertrophic scars, benign skin conditions to premalignant conditions. Further prospective clinical trial with large population group with long term follow-up can help us identify cure rates with number of treatment session required for remission and recurrence rates.

\section{REFERENCES}

1. Farhangian ME, Snyder A, Huang KE, Doerfler L, Huang WW, Feldman SR. Cutaneous cryosurgery in the United States. Dermatolog Treat. 2016;27:91-4.

2. Zouboulis C. Principles of Cutaneous Cryosurgery: An Update. Dermatology. 1999;198:111-7.

3. Horio T, Miyauchi H, Kim YK, Asada Y. The effect of cryo-treatment on epidermal Langer- hans cells and immune function in mice. Arch Dermal Res. 1994;286:69-71.

4. Zouboulis ChC, Zouridaki E, Wulff A. The treatment of keloids, hypertrophic and atrophic scars. J Eur Acad Dermatol Venereol. 1996;7:22.

5. Rogers HW, Weinstock MA, Harris AR, Hinckley MR, Feldman SR, Fleischer $\mathrm{AB}$, et al. Incidence estimate of non melanoma skin cancer in the united states, 2006. Arch Dermatol. 2010;146:283-7.

6. Mulhem E, Pinelis S. Treatment of non genital warts. Am Fam Physician. 2011;84:288-93.

7. Stefanaki C, Lagogiani I, Kouris A, Kontochristopoulos G, Antonio C, Katsarou A. Cryotherpay versus imiquimod 5\% cream combined with keratolytic lotion in cutaneous warts in children: a randomized study. J Dermatology Treat. 2016;27:80-2.

8. Khozeimeh F, Jabbari Azad F, Mahboubi Oskouei Y, Jafari M, Tehranian S, et al. Intralesional immunotherapy compared to cryotherapy in the treatment of warts. Int J Dermatol. 2017;56:474-8.

9. Choi JY, Park JH, Oh SH, Lee JH, Lee DY, Yang JM. Efficacy of Punch Reduction Prior to Cryotherapy in Patients with Viral Warts: A Case-Control Study in a Single Tertiary Center. Dermatology. 2017;29:200-5.

10. Bruggink SC, Waagmeester SC, Gussekloo J, Assendelft WJ, Eekhof JA. Choices in the treatment of cutaneous warts: a survey among Dutch GP. Fam Pract. 2010;27:549-53.

11. Meymandi SS, Moosazadeh M, Rezazadeh A. Comparing Two Methods of Cryotherapy and Intense Pulsed Light with Triamcinolone Injection in the treatmentof Keloid and Hypertrophic Scars: A Clinical Trial. Osong Public Health Res Prospect. 2016;7:313-9.

12. Weshahy AH, Abdel Hay R. Cryosurgery and intralesional steroid injection: a good combination therapy for treatment of keloids and hypertrophic scars. Dermatol Ther. 2012;25:273-6.

13. Mari W, Alsabri SG, Tabal N, Younes S, Sherif A, Simman R. Insights on Understanding of Keloid Scar: Article Review. Am Coll Clin Wound Spec. 2016;7:1-7.

14. Rusciani L, Paradisi A, Alfano C, Chiummariello S, Rusciani A. Cryotherapy in the treatment of keloids. J Drugs Dermatol. 2006;5:591-5.

15. López-Carvajal L, Cardona-Arias JA, Zapata-Cardona MI, SánchezGiraldo V, Vélez ID. Efficacy of cryotherapy for the treatment of cutaneous leishmaniasis: meta-analyses of clinical trials. Infect Dis. 2016;16:360

16. Mastrolonardo M. Topical diclofenac 3\% gel plus cryotherapy for treatment of multiple and recurrent actinic keratoses. Clin Exp Dermatol. 2009;34:33-5.

17. Kaufmann R, Spelman L, Weightman W, Reifenberger J, Szeimies RM, Verhaeghe E, et al. Multicentric intraindividual randomized trial of topical methyl aminolaevulinate-photodynamic therapy vs. cryotherapy for multiple actinic keratoses on the extremities. Clin Exp Dermatol. 2009;34:33-5.

18. Rivas-Tolosa N, Ortiz-Brugués A, Toledo-Pastrana T, Baradad M, Traves V, Soriano V et al. Local cryosurgery and imiquimod: A successful combination for the treatment of locoregionalcutaneous metastasis of melanoma: A case series. J Dermatol 2016; 43(5):553-6.

19. Xu J, Li J, Zhou X, Zeng J, Yao F, Wang Y, Mu F. Cryotherapy for local recurrent dermatofibrosarcoma protuberans: experience in 19 patients. Cryobiology. 2014;68:134-8.

20. Rezende KM, Moraes Pde C, Oliveira LB, Thomaz LA, Junqueira JL, Bönecker M. Cryosurgery as an effective alternative for treatment of oral lesions in children. Braz Dent J. 2014;25:352-6.

Copyright by Deeptara Pathak Thapa, et al. This is an open-access article distributed under the terms of the Creative Commons Attribution License, which permits unrestricted use, distribution, and reproduction in any medium, provided the original author and source are credited.

Source of Support: Nil, Conflict of Interest: None declared. 